\title{
Empathy, emotional intelligence, and communication in Nursing: The moderating effect of the organizational factors*
}

\author{
María del Carmen Giménez-Espert ${ }^{1}$ \\ (1) https://orcid.org/0000-0002-2095-8836 \\ Elena Castellano-Rioja² \\ (D) https://orcid.org/0000-0003-3430-1330 \\ Vicente Javier Prado-Gascó ${ }^{1}$ \\ (D) https://orcid.org/0000-0002-2108-2186
}

Objective: to evaluate the relation and the moderating effect of the organizational factors on the attitudes towards communication, empathy, and emotional intelligence in the nurses. Method: a cross-sectional study was conducted with a convenience sample of 268 nurses from Valencia, Spain. The attitudes towards communication were evaluated by means of the specifically designed instrument, those towards empathy with the Jefferson's Scale of Empathy for Nursing Students, and those towards emotional intelligence by means of the Trait Meta-Mood Scale, consisting of 24 items. The effect of the studied variables was assessed by means of ANOVA, multiple linear regression models were applied, and the moderating effect was analyzed using PROCESS. Results: there are statistically significant differences based on the type on contract (permanent); and statistically significant differences were found in the cognitive dimension of the attitudes towards communication. Regarding the regression models, the perspective taking dimension of empathy was the main predictive variable th the dimensions of the attitudes towards communication. Finally, a moderating effect of the type of contract was evidenced in the effect of emotional reparation over the cognitive dimension of the attitudes towards communication. Conclusion: the organizational factors exert an influence on the attitudes towards communication, empathy, and emotional intelligence.

Descriptors: Communication; Contracts; Emotional Intelligence; Empathy; Nursing Service, Hospital.

\section{How to cite this article}

Giménez-Espert MC, Castellano-Rioja E, Prado-Gascó VJ. Empathy, emotional intelligence, and communication in Nursing: The moderating effect of the organizational factors. Rev. Latino-Am. Enfermagem. 2020;28:e3333. [Access ]; Available in: month day year . DOI: http://dx.doi.org/10.1590/1518-8345.3286.3333. 


\section{Introduction}

Communication is a complex, multi-dimensional, and dynamic process, which refers to developing the means of interaction in an effective and efficient way $^{(1)}$; it constitutes itself as one of the most important indicators to assess the quality of Nursing care ${ }^{(2-}$ 3). It is for this reason that the Joint Commission International (JCI), as a governmental organization for the global accreditation of the best practices related to quality and to patients' safety, identifies inadequate communication among the most common causes of adverse events. Effective communication helps to improve the care actions(4) and the patients' health results ${ }^{(1,5)}$, as well as it contributes to the team's satisfaction and to organizational effectiveness ${ }^{(6)}$. However, despite its importance, studies have barely been developed on the nurses' communication with the patients in the hospital general context ${ }^{(6)}$, in clear opposition to the case of Oncology and in long-term care settings(7), ignoring other situations or realities.

Studying communication as a human conduct inevitably lies on evaluating the attitudes towards such conduct $^{(8)}$. Additionally, in developing communication, Emotional Intelligence (EI from now on) ${ }^{(9)}$ and empathy ${ }^{(10)}$ play a fundamental role. In this sense, there are studies on the relations of the attitudes towards communication, $\mathrm{EI}$, and empathy ${ }^{(11-12)}$. These variables can be influenced by intrinsic and extrinsic factors, like the type of service where the nurses work (general hospitalization or special services) and the type of contract (permanent or temporary) $)^{(13-14)}$. Work uncertainty ${ }^{(15)}$, related to the type of contract, as well as the stress level in the service (general hospitalization or special services), can hinder communication; but EI and empathy facilitate communication even in stressful moments(16), hence their study is considered fundamental. However, despite their importance, we have not found in the literature any study which analyses the relation and moderating effect of these extrinsic factors (type of service and the nurses' contracts) on the attitudes towards communication, empathy, and EI in the nurses. It is for this reason that the main objective of our paper is to analyze the impact of these factors.

\section{Method}

A cross-sectional study was designed, with a convenience sample consisting of 286 nurses from 3 hospitals in Valencia, Spain. The calculation for the sample size was performed according to the population of 2,000 nurses who worked in the participating hospitals, taking into account a $95 \%$ confidence interval and an alpha error of 5.9\%, a sample size of 243 nurses being necessary. Eventually, the study's sample size was 286 nurses. The inclusion criteria were the following: being an active working nurse in the selected hospitals and having expressed their informed and voluntary consent to participate. The exclusion criteria were the following: being on vacation, time-off, and leave periods during the three weeks of data collection. In the active working situation of the nurses, the type of contract (temporary and permanent) was considered. In Spain, a permanent contract offers more stability because the nurses have passed a selective process, thus obtaining an appointment to perform their duties permanently. In addition, the nurses who hold this condition can participate in internal promotion and staff mobility processes. In the case of temporary contracts, the nurse is appointed by the health services due to need or urgency, or for developing programs of a temporary nature; the job, therefore, is performed for a limited period of time ${ }^{(17)}$.

Data collection was conducted by means of a selfapplied instrument. The participants had to answer based on a Likert format with five options, ranging from $1=$ Totally disagree to $5=$ Totally agree. The instrument contained the following scales:

- Sociodemographic data: work center, service, gender, age, and working situation.

- A questionnaire on the nurses' attitudes towards communication (ACO)(18-19). It consists of 25 items grouped into three dimensions: affective, cognitive, and conative, to assess the attitudes towards communication. This instrument has shown adequate psychometric properties: SatorraBentler (S-B $\chi 2)$; Degrees of Freedom (DoF) S-B $\chi 2($ DoF $)=525.09$ (272); $\chi 2($ DoF $)=4.90 ;$ Root Mean Square Error of Approximation (RMSEA); Confidence Interval (CI); RMSEA (CI) $=0.045$ (0.0370.057); Comparative Fit Index (CFI), CFI $=0.91$, Non-Normalized Fit Index (NNFI), NNFI=0.90, IFI=0.91; Affective: Cronbach's alpha confidence interval $\quad(\mathrm{CI} \alpha)=0.95 \quad(0.94-0.96) ; \quad$ Compound Reliability Coefficient (CRC), $C R C=0.95$; Average Variance Extracted (AVE), $A V E=0.60$; Conative: $\mathrm{CI} \alpha=0.92 \quad(0.90-0.93), \quad \mathrm{CRC}=0.91, \quad \mathrm{AVE}=0.53$; Cognitive: $\quad \mathrm{CI} \alpha=0.85 \quad(0.82-0.87), \quad \mathrm{CRC}=0.85$; $A V E=0.58^{(18)}$.

- The Jefferson's Scale of Empathy for Nursing Students adapted from Jefferson's Scale of Physician Empathy (JSPE) (20) was translated by the research team. Jefferson's medical empathy scale was adapted 
from Nursing students to the nurses; in its original version(20), it had 19 items (JSNE) grouped into three factors to assess empathy. It presents adequate psychometric properties: Satorra-Bentler (S-B X2); Degrees of Freedom (DoF); S-B X2(DoF)=174.74 (87); $\mathrm{X} 2(\mathrm{DOF})=3.82$; RMSEA $(\mathrm{CI})=0.047 \quad(0.037$ $0.057) ; \quad C F I=0.92, \quad N N F I=0.90, \quad$ IFI $=0.91$; Perspective taking: Cronbach's alpha confidence interval $(\mathrm{ICa})=0.87(0.85-0.89) ; \mathrm{CRC}=0.88 \mathrm{AVE}=0.47$; Compassionate care: $\mathrm{ICa}=0.78(0.75-0.81)$; $\mathrm{CRC}=0.78$; $\mathrm{AVE}=0.48$; Thinking as the patient: $\mathrm{ICa}=0.76(0.71-0.80) ; \mathrm{CRC}=0.76 ; \mathrm{AVE}=0.61^{(21)}$.

- The Trait Meta-Mood Scale (TMMS24) is a scale consisting of 24 items grouped into three dimensions, the Spanish version having been adapted by Fernández-Berrocal and to the Nursing context ${ }^{(22)}$ to assess EI. It presents adequate psychometric properties in the Nursing population: SatorraBentler (S-B X2); Degrees of Freedom (DoF); S-B $\quad \chi 2($ DoF $)=370.20 \quad(149) ; \quad \chi 2($ DoF $)=3.58$; RMSEA $\quad(I C)=0.057 \quad(0.050-0.65) ; \quad C F I=0.91$; NNFI $=0.90$; IFI $=0.91$; Emotional care: Cronbach's alpha confidence interval $(\mathrm{CI} \alpha)=0.80$ (0.77-0.83), $\mathrm{CRC}=0.80 ; \quad \mathrm{AVE}=0.45$; Emotional clarity: $\mathrm{CI} \alpha=0.87 \quad(0.85-0.89), \quad \mathrm{CRC}=0.87 ; \quad \mathrm{AVE}=0.46$; Emotional reparation: $\mathrm{CI} \alpha=0.85 \quad(0.82-0.87)$; $\mathrm{CRC}=0.85 ; \mathrm{AVE}=0.49^{(21)(23)}$.

Firstly, the differences in the study variables were analyzed according to the type of contract and service by means of the Student's $t$ test. Multiple models of hierarchical linear regression were calculated considering the type of contract (temporary and permanent) and service (general hospitalization and special services). Finally, the moderating effect was calculated of the type of contract and service on the effect of JSNE and of TMMS24 over ACO by means of 18 different models, considering each of the independent variables (dimensions from JSNE and from TMMS24) over the criteria variables (ACO dimensions). These analyses were performed using the PROCESS(24) macro software installed in the Statistical Package for the Social Sciences (SPSS), version 23, designed to test moderation by means of the direct evaluation of the importance of the indirect effect of the independent variable on the dependent variable through two moderators: Working situation (M) and Type of service (W). The moderating effect (with $n=5,000$ bootstrap samples) is demonstrated when the corrected confidence interval ( $95 \%)$ of the indirect effect does not include zero(24). All these analyses were performed using the Statistical Package for the Social Sciences (SPSS), version 23.

The study was approved by the Research Ethics Committee of the University of Valencia (H143203222268924) and by the Committees of Ethics in Clinical Research (Comités de Ética de la Investigación Clínica, CEIC) of the selected hospitals. All the individuals who agreed to participate had previously received detailed information about the study, as well as on the confidentiality of the data provided.

\section{Results}

A total of 268 nurses answered the questionnaires and 12 were excluded due to not having completed them properly; consequently, 286 questionnaires were analyzed. Regarding the sociodemographic characteristics of the participants, their age ranged from 23 to 63 years old, with a mean of 45.25 (Standard Deviation=10.97). In terms of gender distribution, $74.1 \%$ (213) are women and $25.5 \%(73)$ are men. Regarding the working situation of the participants, $47.9 \%$ (137) are temporary workers, whereas $52.1 \%$ (149) have a permanent job position. As regards the type of service, $56.6 \%$ (162) works in hospitalization units and $43.4 \%$ (124) in special services.

According to the differences in ACO, JSNE, and TMMS24 based on the type of contract and service, statistically significant differences $(p \leq .05)$ were only found in the cognitive dimension ( $t=-2.41$; $\mathrm{p}=.017 ; \mathrm{\eta} 2=.02$ ) of the ACO scale considering the type of contract. The Nursing staff with a permanent working situation presented a slightly higher score (Mean=4.52, Standard Deviation=0.76) than the temporary personnel (Mean $=4.26$, Standard Deviation $=0.98)($ Table 1$)$.

On the other hand, when considering the type of service, no significant differences were observed between general hospitalization and special services (Table 2).

Subsequently, the multiple linear regression models were analyzed based on the type of contract and service. The predictive value of EI and of empathy on the dimensions of the ACO instrument considering the type of contract (temporary or permanent) and of service (general hospitalization or special service) was analyzed by means of hierarchical regression models. In all cases, in the first step the empathy dimensions (JSNE) were included and, in the second, those of EI (TMMS24). 
Table 1 - Dimensions of the attitudes towards communication, Jefferson's Scale of Empathy for Nurses and Trait Scale of Meta-knowledge on Emotional States (or Trait Meta-Mood Scale) according to the type of contract. Valencia, Spain, 2016

\begin{tabular}{|c|c|c|c|c|c|c|c|c|}
\hline & \multirow[t]{2}{*}{ Dimensions } & \multicolumn{2}{|c|}{ Temporary contract } & \multicolumn{2}{|c|}{ Permanent contract } & \multirow[t]{2}{*}{$t$ test $^{*}$} & \multirow[t]{2}{*}{$\begin{array}{c}p \\
\text { value }^{\dagger}\end{array}$} & \multirow[t]{2}{*}{ Effect $^{\ddagger}$} \\
\hline & & Mean & Standard Deviation & Mean & Standard Deviation & & & \\
\hline \multirow{3}{*}{$\begin{array}{l}\text { Attitudes towards } \\
\text { communication }\end{array}$} & Affective & 1.71 & 0.96 & 1.57 & 0.82 & 1.25 & 0.21 & $\S$ \\
\hline & Conative & 4.02 & 0.86 & 4.18 & 0.79 & -1.56 & 0.12 & $\S$ \\
\hline & Cognitive & 4.26 & 0.98 & 4.52 & 0.76 & -2.41 & $0.017 \|$ & 0.02 \\
\hline \multirow{3}{*}{$\begin{array}{l}\text { Jefferson's empathy } \\
\text { scale }\end{array}$} & Perspective taking & 4.49 & 0.55 & 4.47 & 0.62 & 0.35 & 0.73 & $\S$ \\
\hline & Compassionate care & 1.98 & 0.90 & 1.95 & 0.89 & 0.21 & 0.83 & $\S$ \\
\hline & Thinking as the patient & 2.03 & 1.04 & 2.08 & 1.06 & -0.38 & 0.70 & $\S$ \\
\hline \multirow{3}{*}{ Trait Meta Mood Scale } & Emotional care & 3.46 & 0.74 & 3.57 & 0.71 & -1.21 & 0.23 & $\S$ \\
\hline & Emotional clarity & 3.76 & 0.61 & 3.74 & 0.73 & 0.30 & 0.77 & $\S$ \\
\hline & Emotional reparation & 3.77 & 0.74 & 3.77 & 0.76 & 0.05 & 0.96 & $\S$ \\
\hline
\end{tabular}

${ }^{*} \mathrm{t}$-test; ${ }^{+} p$ value resulting from the Levene test; ${ }^{\prime}$ Effect; sIt was not calculated because there were no significant differences; $\mathrm{p} \leq 0.01 ; " \mathrm{p} \leq 0.05$

Table 2 - Dimensions of the attitudes towards communication, Jefferson's Scale of Empathy for Nurses and Trait Scale of Meta-knowledge on Emotional States (or Trait Meta-Mood Scale) according to the type of service. Valencia, Spain, 2016

\begin{tabular}{|c|c|c|c|c|c|c|c|c|}
\hline & \multirow[t]{2}{*}{ Dimensions } & \multicolumn{2}{|c|}{ General hospitalization } & \multicolumn{2}{|c|}{ Special service } & \multirow[t]{2}{*}{ t test* } & \multirow[t]{2}{*}{$\begin{array}{c}p \\
\text { value }^{\dagger}\end{array}$} & \multirow[t]{2}{*}{ Effect $^{\ddagger}$} \\
\hline & & Mean & Standard Deviation & Mean & Standard Deviation & & & \\
\hline \multirow{3}{*}{$\begin{array}{l}\text { Attitudes towards } \\
\text { communication }\end{array}$} & Affective & 1.59 & 0.88 & 1.69 & 0.91 & -.87 & 0.39 & $\S$ \\
\hline & Conative & 4.12 & 0.80 & 4.08 & 0.87 & 0.31 & 0.76 & $\S$ \\
\hline & Cognitive & 4.43 & 0.89 & 4.35 & 0.88 & .75 & 0.46 & $\S$ \\
\hline \multirow{3}{*}{$\begin{array}{l}\text { Jefferson's empathy } \\
\text { scale }\end{array}$} & Perspective taking & 4.48 & 0.58 & 4.49 & 0.60 & -.14 & 0.89 & $\S$ \\
\hline & Compassionate care & 2.05 & 0.92 & 1.85 & 0.85 & 1.83 & 0.07 & $\S$ \\
\hline & Thinking as the patient & 2.05 & 1.09 & 2.06 & 1.00 & -0.05 & 0.96 & $\S$ \\
\hline \multirow{3}{*}{ Trait Meta Mood Scale } & Emotional care & 3.57 & 0.75 & 3.45 & 0.68 & 1.25 & 0.21 & $\S$ \\
\hline & Emotional clarity & 3.79 & 0.67 & 3.69 & 0.67 & 1.22 & 0.22 & $\S$ \\
\hline & Emotional reparation & 3.75 & 0.79 & 3.80 & 0.70 & -0.54 & 0.59 & $\S$ \\
\hline
\end{tabular}

${ }^{* t}$-test; ${ }^{+} p$ value resulting from the Levene test; ${ }^{*}$ Effect; ${ }^{\text {IIt }}$ was not calculated because there were no significant differences; $\mathrm{p} \leq 0.01 ; \mathrm{p} \leq 0.05$

Considering the type of contract (Table 3), in the case of those individuals with a temporary contract, the variables taken into account were capable of explaining $7 \%$ of the affective dimension $\left(R_{\text {adjusted }}^{2}=0.07, p \leq 0.05\right), 11 \%$ of the cognitive dimension $\left(R_{\text {adjusted }}^{2}=0.11, p \leq 0.01\right)$, and $17 \%$ of the conative dimension $\left(R_{\text {adjusted }}^{2}=0.17, p \leq 0.01\right)$. On the other hand, considering those individuals with a permanent contract, the variables taken into account explained $14 \%$ of the affective dimension ( $\left.R_{\text {adjusted }}^{2}=0.14, p \leq 0.01\right), 16 \%$ of the cognitive dimension ( $\left.R_{\text {adjusted }}^{2}=0.16, p \leq 0.01\right)$, and $29 \%$ of the conative dimension $\left(R_{\text {adjusted }}^{2}=0.29, p \leq 0.01\right)$.

Specifically, in the case of the workers with a temporary contract, only the perspective taking dimension from JSNE for the prediction of the conative ( $\beta=0.30$; $p \leq 0.01)$ and cognitive $(\beta=0.28 ; p \leq 0.05)$ dimensions, and the emotional clarity dimension from TMMS24 for the prediction of the affective $(\beta=-0.23 ; p \leq 0.05)$ and conative $(\beta=0.22 ; p \leq 0.05)$ dimensions turned out to be significant. Regarding the workers with a permanent contract, it was observed that perspective taking in JSNE positively and significantly predicted the three dimensions from ACO: affective, cognitive, and conative $(\beta=0.15 ; p \leq 0.01, \beta=0.41 ; p \leq 0.001$, $\beta=0.54 ; p \leq 0.001)$. The emotional clarity dimension from TMMS24 positively and significantly predicted the affective dimension from ACO ( $\beta=0.13 ; p \leq 0.05)$, and the compassionate care dimension positively and significantly predicted the conative dimension from ACO ( $\beta=0.22 ; p \leq 0.05)$ (Table 3).

In the type of service model (Table 4 ), in the case of the general hospitalization workers, the variables taken into account were capable of explaining $15 \%$ of the affective dimension ( $\left.R_{\text {adjusted }}^{2}=0.15, p \leq 0.01\right), 17 \%$ of the cognitive dimension $\left(R_{\text {adjusted }}^{2}=0.17, p \leq 0.01\right)$, and $25 \%$ of the conative dimension $\left(R_{\text {adjusted }}^{2}=0.17, p \leq 0.01\right)$. On the other hand, regarding the nurses who work in special services, the variables taken into account explained $6 \%$ of the affective dimension $\left(R_{\text {adjusted }}^{2}=0.06, p \leq 0.05\right), 8 \%$ of the cognitive dimension ( $\left.R_{\text {adjusted }}=0.08, p \leq 0.05\right)$, and $19 \%$ of the conative dimension $\left(R_{\text {adjusted }}^{2}=0.19, p \leq 0.01\right)$.

Specifically in the case of the general hospitalization services, the perspective taking dimension from JSNE positively and significantly predicted the cognitive $(\beta=0.36 ; p \leq 0.001)$ and conative $(\beta=0.40$; $\mathrm{p} \leq 0.001$ ) dimensions from ACO and negatively predicted the affective dimension from ACO $(\beta=-0.25 ; p \leq 0.05)$. The emotional clarity dimension fromTMMS24 negatively and significantly predicted the affective dimension from ACO $(\beta=-0.35 ; p \leq 0.001)$ and positively predicted the cognitive $(\beta=0.24 ; p \leq 0.05)$ and conative $(\beta=0.24$; $p \leq 0.05$ ) dimensions. In the case of the special services, only the perspective taking dimension from JSNE positively and significantly predicted the three dimensions from ACO: affective, cognitive, and conative $(\beta=0.15 ; p \leq 0.01$, $\beta=0.26 ; p \leq 0.05, \beta=0.35 ; p \leq 0.01$ ) (Table 4). 
Table 3 - Hierarchical regression analysis for the dimensions from JSNE and from TMMS24 over the dimensions from ACO (affective, cognitive, and conative) based on the type of contract. Valencia, Spain, 2016

\begin{tabular}{|c|c|c|c|c|c|c|}
\hline \multirow{2}{*}{$\begin{array}{c}\text { Variable } \\
\text { Predictors }\end{array}$} & \multicolumn{2}{|c|}{ Affective } & \multicolumn{2}{|c|}{ Cognitive } & \multicolumn{2}{|c|}{ Conative } \\
\hline & $\Delta \mathbf{R}^{2}$ & B & $\Delta \mathbf{R}^{2}$ & $\beta$ & $\Delta \mathbf{R}^{2}$ & B \\
\hline Step 1 Temporary & 0.06 & & $0.13^{*}$ & & $0.17^{\dagger}$ & \\
\hline Perspective taking & & -0.19 & & $0.32^{\dagger}$ & & $0.40^{+}$ \\
\hline Compassionate care & & 0.07 & & -0.09 & & 0.07 \\
\hline Thinking as the patient & & 0.06 & & 0.01 & & -0.13 \\
\hline Step 2 Temporary & 0.06 & & 0.03 & & 0.05 & \\
\hline Perspective taking & & -0.22 & & $0.28^{\ddagger}$ & & $0.30^{*}$ \\
\hline Compassionate care & & 0.04 & & -0.09 & & 0.06 \\
\hline Thinking as the patient & & 0.07 & & 0.01 & & -0.12 \\
\hline Emotional care & & 0.08 & & -0.03 & & -0.06 \\
\hline Emotional clarity & & $-0.23^{\ddagger}$ & & 0.18 & & $0.22^{\ddagger}$ \\
\hline Emotional reparation & & 0.17 & & -0.01 & & 0.07 \\
\hline Total $R_{\text {adjusted }}^{2}$ & $0.07^{\ddagger}$ & & $0.11^{\dagger}$ & & $0.17^{\dagger}$ & \\
\hline Step 1 Permanent & $0.14^{\dagger}$ & & $0.17^{\dagger}$ & & $0.29^{\dagger}$ & \\
\hline Perspective taking & & $0.14^{+}$ & & $0.38^{\dagger}$ & & $0.54^{+}$ \\
\hline Compassionate care & & 0.11 & & 0.01 & & $0.22^{\ddagger}$ \\
\hline Thinking as the patient & & 0.08 & & -0.08 & & -0.17 \\
\hline Step 2 Permanent & 0.05 & & 0.03 & - & 0.04 & \\
\hline Perspective taking & & $0.15^{*}$ & & $0.41^{\dagger}$ & & $0.54^{+}$ \\
\hline Compassionate care & & 0.10 & & -0.00 & & $0.22^{\ddagger}$ \\
\hline Thinking as the patient & & 0.08 & & -0.07 & & -0.17 \\
\hline Emotional care & & 0.12 & & -0.12 & & -0.15 \\
\hline Emotional clarity & & $0.13^{\ddagger}$ & & 0.20 & & 0.00 \\
\hline Emotional reparation & & 0.13 & & -0.18 & & 0.15 \\
\hline Total $R_{\text {adjusted }}^{2}$ & $0.14^{\dagger}$ & & $0.16^{\dagger}$ & & $0.29^{\dagger}$ & \\
\hline
\end{tabular}

Table 4 - Hierarchical regression analysis for the dimensions from JSNE and from TMMS24 over the dimensions from ACO (affective, cognitive, and conative) based on the type of service. Valencia, Spain, 2016

\begin{tabular}{|c|c|c|c|c|c|c|}
\hline \multirow{2}{*}{$\begin{array}{c}\text { Variable } \\
\text { Predictors }\end{array}$} & \multicolumn{2}{|c|}{ Affective } & \multicolumn{2}{|c|}{ Cognitive } & \multicolumn{2}{|c|}{ Conative } \\
\hline & $\Delta \mathbf{R}^{2}$ & $\beta$ & $\Delta \mathbf{R}^{2}$ & $\beta$ & $\Delta \mathbf{R}^{2}$ & $\beta$ \\
\hline Step 1 General hospitalization & 0.09 & & $0.16^{*}$ & & $0.23^{*}$ & \\
\hline Perspective taking & & $-0.27^{\dagger}$ & & $0.36^{*}$ & & $0.48^{*}$ \\
\hline Compassionate care & & 0.03 & & -0.05 & & $0.23^{\ddagger}$ \\
\hline Thinking as the patient & & 0.05 & & -0.03 & & $-0.18^{\ddagger}$ \\
\hline Step 2 General hospitalization & $0.01^{\dagger}$ & & 0.05 & & $0.05^{\ddagger}$ & \\
\hline Perspective taking & & $-0.25^{\ddagger}$ & & $0.36^{*}$ & & $0.40^{*}$ \\
\hline Compassionate care & & 0.01 & & -0.03 & & $0.21^{\ddagger}$ \\
\hline Thinking as the patient & & 0.03 & & -0.03 & & -0.15 \\
\hline Emotional care & & 0.17 & & -0.11 & & -0.16 \\
\hline Emotional clarity & & $-0.35^{*}$ & & $0.24^{\ddagger}$ & & $0.24^{\ddagger}$ \\
\hline Emotional reparation & & $0.21^{\ddagger}$ & & -0.18 & & 0.03 \\
\hline Total $R_{\text {adjusted }}^{2}$ & $0.15^{*}$ & & $0.17^{*}$ & & $0.25^{*}$ & \\
\hline Step 1 Special services & $0.11^{\ddagger}$ & & $0.13^{\ddagger}$ & & $0.22^{*}$ & \\
\hline Perspective taking & & $0.14^{*}$ & & $0.31^{\dagger}$ & & $0.43^{*}$ \\
\hline Compassionate care & & 0.11 & & -0.07 & & $0.02^{\ddagger}$ \\
\hline Thinking as the patient & & 0.08 & & -0.01 & & $-0.11^{\ddagger}$ \\
\hline Step 2 Special services & 0.02 & & 0.01 & & 0.03 & \\
\hline
\end{tabular}


Table 4 - (continuation)

\begin{tabular}{|c|c|c|c|c|c|c|}
\hline \multirow{2}{*}{$\begin{array}{c}\text { Variable } \\
\text { Predictors }\end{array}$} & \multicolumn{2}{|c|}{ Affective } & \multicolumn{2}{|c|}{ Cognitive } & \multicolumn{2}{|c|}{ Conative } \\
\hline & $\Delta \mathbf{R}^{2}$ & $\beta$ & $\Delta \mathbf{R}^{2}$ & $\beta$ & $\Delta \mathbf{R}^{2}$ & $\beta$ \\
\hline Perspective taking & & $0.15^{\dagger}$ & & $0.26^{\ddagger}$ & & $0.35^{\dagger}$ \\
\hline Compassionate care & & 0.10 & & -0.07 & & 0.01 \\
\hline Thinking as the patient & & 0.08 & & -0.02 & & -0.11 \\
\hline Emotional care & & 0.12 & & 0.03 & & -0.02 \\
\hline Emotional clarity & & 0.13 & & -0.00 & & -0.06 \\
\hline Emotional reparation & & 0.13 & & 0.12 & & 0.20 \\
\hline Total $R_{\text {adjusted }}^{2}$ & $0.06^{\ddagger}$ & & $0.08^{\ddagger}$ & & $0.19^{*}$ & \\
\hline
\end{tabular}

${ }^{*} \mathrm{p} \leq .001 ;{ }^{\dagger} \mathrm{p} \leq .01 ;{ }^{\ddagger} \mathrm{p} \leq .05$

Finally, based on the analysis of the type of contract and service over the effect of empathy and EI on the attitudes towards communication, a moderating effect of the working situation on the effect of emotional reparation over the cognitive dimension of the ACO instrument was only observed, since it is demonstrated when the corrected confidence interval $(95 \%)$ of the indirect effect does not include zero $^{(23)}$ (Lower confidence interval $=0.0440$; Higher confidence interval $=0.6152)$. Specifically, emotional reparation seems to be a better predictor in the case of the permanent contracts $(\beta=0.21 ; p=0.03)$ than in the temporary ones $(\beta=0.14 ; p=0.10)$. (Effect $_{\text {permanent }}=0.22 ; \quad \mathrm{SE}_{\text {permanent }}=0.10 ; \quad \mathrm{t}_{\text {permanent }}=2.15$, $p_{\text {permanent }}=0.03 ; \quad \mathrm{Effect}_{\text {temporary }}=0.14 ; \quad \mathrm{SE}_{\text {temporary }}=0.10$; $\mathrm{t}_{\text {temporary }}=1.43 p_{\text {permanent }}=0.15$ )

\section{Discussion}

The communication, empathy and EI skills had a direct repercussion on the quality of care ${ }^{(2-3)}$. It was important to consider external factors which were more related to the organizational aspects, like the type of contract and services, which could have exerted an influence on those skills(13-14). However, there are still no studies which analyze these relations; so the objective of this research was to know how the type of contract and service affected the attitudes towards communication, empathy, and EI in the nurses.

The Nursing literature presents studies on the influence of the organizational aspects on their work satisfaction and on the nurses' intention to leave their profession, together with the appearance of negative feelings of impotence and uselessness(25-26). Other studies assess quality of life in the work of the Nursing personnel based on the type of contract and on the type of institution where they work ${ }^{(6)}$, as well as the psychosocial factors and the mental burden of the nurses related to the care unit where they work ${ }^{(27)}$. These studies show the need to foster work environments where work security favors satisfaction, professional development, and personal well-being. In this research, apart from approaching the aspects related to the extrinsic factors (type of contract and service), intrinsic factors like communication, empathy, and EI are also considered.

The results of our study show that there only seems to be statistically significant differences in the case of the cognitive dimension from the ACO scale considering the type of contract; those professionals with a permanent contract seem to present slightly higher levels than those with a temporary contract.

Likewise, the empathy and EI dimensions are better predictors of the attitudes towards communication in the case of individuals with a permanent contract than in those with a temporary contract. Similarly, those variables were also better predictors in the case of the general hospitalization services compared to the special services. In general, the variable which best seems to predict the attitudes towards communication is perspective taking (JSNE), followed by emotional clarity. Finally, a moderating effect of the working situation on the effect of emotional reparation was observed over the cognitive dimension of the ACO instrument; in this sense, emotional reparation seems to be a better predictor in the case of the permanent contracts.

These results might indicate that work uncertainty ${ }^{(15)}$, related to the type of contract, as well as the stress level in the service (general hospitalization or special services), can hinder communication. In this study we found studies which relate work insecurity and stress level in the service as negative factors for providing quality Nursing care and for the nurses' wellbeing(6,25-26). The results of this research also showed that empathy and EI constitute themselves as protection elements in these situations ${ }^{(16)}$.

Despite the contributions of this research, it does have limitations: the sampling procedures are not probabilistic, as well as the geographical context, since the sample consists only of nurses working in hospitals of Valencia, Spain. It is due to these aspects that the results are not representative of all the Nursing 
professionals, which hinders the generalization of the results found. In the future it is proposed to conduct a stratified probabilistic sampling, considering different geographical areas, thus improving data generalization.

\section{Conclusion}

Nurses with a permanent contract seem to present slightly higher levels in the cognitive dimension from the ACO scale, which evidences the importance given to the communication with the patients and/or families. In the case of the permanent contracts and of the general hospitalization services, the empathy and EI dimensions are better predictors of the attitudes towards communication.

Our study shows that the type of contract and service exert an influence on the attitudes towards communication, empathy, and EI, with the consequent possibility of arising as risk or protection factors. Thus, improving the working conditions of the Nursing professionals will translate into the improvement of their attitudes towards communication and, therefore, of the quality of the Nursing care.

\section{Acknowledgments}

We thank the nurses who participated in this study by completing the instrument.

\section{References}

1. Almeida RT, Ciosak SI. Communication between the elderly person and the Family Health Team: is there integrality? Rev. Latino-Am. Enfermagem. 2013;21(4):88490. doi:10.1590/S0104-11692013000400008

2. Araújo IMDA, Silva RMD, Bonfim IM, Fernandes AFC. Nursing communication in nursing care to mastectomized women: a grounded theory study. Rev. Latino-Am. Enfermagem. 2010;18(1):54-60. doi: 10.1590/S010411692010000100009

3. Müggenburg MC, Riveros-Rosas A. Interacción enfermera-paciente y su repercusión en el cuidado hospitalario: Parte I. Enferm Univ. [Internet]. 2012 Mar [Acceso 11 feb 2020];9(1):36-44. Disponible en: http://www.scielo.org.mx/scielo.php?script=sci_arttext \&pid=S1665-70632012000100005

4. Santos JLG, Copelli FHS, Balsanelli AP, Sarat CNF, Menegaz JC, Trotte LAC, et al. Interpersonal communication competence among nursing students. Rev. Latino-Am. Enfermagem. 2019;27:e3207. doi: 10.1590/1518-8345.3226.3207 .

5. Juvé-Udina ME, Pérez EZ, Padrés NF, Samartino MG, García MR, Creus MC, et al. Basic Nursing Care: Retrospective Evaluation of Communication and
Psychosocial Interventions Documented by Nurses in the Acute Care Setting. J Nurs Scholarsh. 2014;46(1):65-72. doi: $10.1111 /$ jnu.12062

6. Quintana-Zavala MO, Paravic-Klijn, T, SaenzCarrillo KL. Quality of life in the workplace for nursing staff at public healthcare institutions. Rev. Latino-Am. Enfermagem. 2016;24:e2713. doi: 10.1590/15188345.1149.2713

7. França JRFDS, Costa SFGD, Lopes MEL, Nóbrega MMLD, França ISXD. The importance of communication in pediatric oncology palliative care: focus on Humanistic Nursing Theory. Rev. Latino-Am. Enfermagem. 2013;21(3):780-6. doi: 10.1590/S010411692013000300018

8. Baron R, Byrne D. Psicología social. 8a ed. Madrid: Prentice-Hall; 2002.

9. Cherry MG, Fletcher I, O'Sullivan H. Exploring the relationships among attachment, emotional intelligence and communication. Med Educ. 2013;47(3):317-25. doi: $10.1111 /$ medu. 12115

10. Cunico L, Sartori R, Marognolli O, Meneghini AM. Developing empathy in nursing students: A cohort longitudinal study. J Clin Nurs. 2012;21(13-14):2016-25. doi: 10.1111/j.1365-2702.2012.04105.x

11. Brunero S, Lamont S, Coates M. A review of empathy education in nursing. Nurs Inq. 2010;17(1):65-74. doi: 10.1111/j.1440-1800.2009.00482.x

12. Agarwal R, Sands DZ, Schneider JD. Quantifying the economic impact of communication inefficiencies in US hospitals. J Healthc Manag. 2010;55(4):265-81.

13. Becker F. Nursing Unit Design and Communication Patterns: What Is "Real" Work?. HERD. 2007;1(1):58-62. 14. O'Leary KJ, Wayne DB, Landler MP, Kulkarni N, Haviley $\mathrm{C}$, Hahn $\mathrm{KJ}$, et al. Impact of localizing physicians to hospital units on nurse-physician communication and agreement on the plan of care. J Gen Intern Med. 2009;24(11):1223-7. doi: 10.1007/s11606-009-1113-7 15. Belda LL. La comunicación, pieza clave en enfermería. Enferm Dermatol. 2012;16:16-9.

16. Arond-Thomas M. Understanding Emotional Intelligence Can Help Alter Problem Behavior. Physician Exec. 2004;30(5):36-9.

17. Ley 55/2003, de 16 de diciembre, del Estatuto Marco del personal estatutario de los servicios de salud. Boletín Oficial del Estado, 17 dic 2003.

18. Giménez-Espert MC, Prado-Gascó VJ. The developmentand psychometric validation of an instrument to evaluate nurses' attitudes towards communication with the patient (ACO). Nurse Educ. Today. 2018; 64:21-32. doi: $10.1016 /$ j.nedt.2018.01.031

19. Giménez-Espert MC, Prado-Gascó, VJ. The moderator effect of sex on attitude toward communication, emotional intelligence, and empathy in the nursing 
field. Rev. Latino-Am. Enfermagem. 2017;25:e2969. doi: 10.1590/1518-8345.2018.2969.

20. Ward J, Schaal M, Sullivan J, Bowen ME, Erdmann JB, Hojat M. Reliability and Validity of the Jefferson Scale of Empathy in Undergraduate Nursing Students. J Nurs Meas. 2009;17(1):73-88. doi: 10.1891/10613749.17.1.73

21. Giménez-Espert MC, Prado-Gascó VJ. The role of empathy and emotional intelligence in nurses' communication attitudes using regression models and fuzzy-set qualitative comparative analysis models (fsQCA). J Clin Nurs. 2018 Jul;27(13-14):2661-72. doi: 10.1111/jocn. 14325

22. Fernandez-Berrocal P, Extremera N, Ramos N. Validity and reliability of the Spanish modified version of the Trait Meta-Mood Scale 1, 2. Psychol Rep. 2004;94(3):751-5. doi: 10.2466/pr0.94.3.751-755

23. Giménez-Espert MC, Prado-Gascó VJ. Emotional intelligence in nurses: The Trait Meta-Mood Scale. Acta Paul Enferm. 2017;30(2):204-9. doi: 10.1590/19820194201700031

24. Bolin JH. Andrew F Hayes (2013). Introduction to Mediation, Moderation, and Conditional Process Analysis: A Regression-Based Approach. New York, NY: The Guilford Press. J Educ Meas. 2014;51(3):335-7. doi: $10.1111 /$ jedm. 12050

25. Alilu L, Zamanzadeh V, Valizadeh $L$, Habibzadeh $H$, Gillespie M. A Grounded theory study of the intention of nurses to leave the profession. Rev. Latino-Am. Enfermagem. 2017;25:e2894. doi: 10.1590/15188345.1638.2894

26. Melo MB, Barbosa MA, Souza PR. Job satisfaction of nursing staff: integrative review. Rev. Latino-Am. Enfermagem. 2011;19(4):1047-55. doi: 10.1590/S010411692011000400026

27. Ceballos-Vásquez P, Rolo-González G, HérnandezFernaud E, Díaz-Cabrera D, Paravic-Klijn T, BurgosMoreno M. Psychosocial factors and mental work load: a reality perceived by nurses in intensive care units. Rev. Latino-Am. Enfermagem. 2015;23(2):315-22. doi: 10.1590/0104-1169.0044.2557 Creative Commons (CC BY).

This license lets others distribute, remix, tweak, and build upon your work, even commercially, as long as they credit you for the original creation. This is the most accommodating of licenses offered. Recommended for maximum dissemination and use of licensed materials. 